\title{
Effects of age on motor preparation and restructuring
}

\author{
NOREEN L. GOGGIN, GEORGE E. STELMACH, and PAUL C. AMRHEIN \\ University of Wisconsin-Madison, Madison, Wisconsin
}

\begin{abstract}
Age-related decrements in motor plan restructuring were investigated. In this experiment older and younger adults performed a discrete aiming task that involved responses that were precued and responses that were modified at the time of an imperative signal. On $75 \%$ of the trials, the precue specified the response stimulus (valid trials) with respect to the movement parameters of arm (left or right) and direction (toward or away). On the remaining $25 \%$ of the trials, the response stimulus was different from the precue (invalid trials) in that the subject was required to modify a planned movement by changing the arm to be used and/or the direction of movement. The older subjects were slower than the younger in both the valid and invalid trials. Across preparatory intervals (PI) of 500,1,000, 1,500, and 2,000 msec, older, but not younger subjects exhibited less reaction time cost for restructuring the motor plan for the direction-change condition than for the other parameter change conditions. Since there was little apparent cost of restructuring, these findings suggest that older adults did not prepare the direction of movement, and thus found it temporally more efficient to alter direction than arm or arm and direction combined.
\end{abstract}

Older adults have demonstrated an inability to use probability information in preparing a response (Gottsdanker, 1980b; Rabbitt, 1984; Rabbitt \& Vyas, 1980) and to maintain movement preparation (Botwinick, Brinley, \& Robbin, 1959; Gottsdanker, 1980a). These findings suggest that older adults may prepare movements in a manner different from that of younger adults. If older adults do not or cannot maintain a specific movement preparation, there should be a differential cost to restructure movements. Heretofore, there has been little evidence to support the notion that older adults differentially prepare limb movements.

Recently, researchers studying motor plan alteration and aging have employed a restructuring or reprogramming paradigm (Rosenbaum \& Kornblum, 1982) that allows for the measurement of the time necessary to alter an existing motor plan according to specific movement parameters, such as arm, direction, and extent (e.g., Larish \& Stelmach, 1982; Stelmach, Goggin, \& Amrhein, 1988). For a person to prepare a motor plan prior to a response, a majority of trials $(75 \%-80 \%)$ administered should represent cases in which the precue and response stimuli are identical (valid trials). Thus, it is assumed that subjects use the precue information to prepare the movement prior to movement initiation. As an example of motor plan development, Plamondon, Stelmach, and Teasdale (1989) postulated that precue information advances the general motor plan into specific parameter settings through a system of generators characterized by transfer functions, gain factors, and time constants.

This research was supported by Grant AGO5154 from the U.S. Public Health Service. Paul C. Amrhein is now at Washington University, St. Louis, MO. Requests for reprints should be sent to George E. Stelmach, Motor Behavior Laboratory, 2000 Observatory Dr., University of Wisconsin-Madison, Madison, WI 53706.
The remaining trials $(20 \%-25 \%)$ represent situations in which the precue and response stimuli vary according to specific movement parameters (invalid trials). In this case, preparation of the precued response is beneficial only to the degree to which prepared parameters need not be changed. When a parameter needs to be changed, there is a cost associated with the time needed to jettison the parameters prepared and the subsequent time needed to assemble new parameters.

Larish and Stelmach (1982, Experiment 2) manipulated movement direction across several long preparatory intervals (PIs) $(1,150-1,600 \mathrm{msec})$ and found that, aside from a constant increase $(80 \mathrm{msec})$ for older over younger subjects, both groups exhibited the same pattern of restructuring. Moreover, Stelmach et al. (1988) manipulated arm, direction, and extent in a restructuring paradigm. Invalid precue reaction time (RT) was $100 \mathrm{msec}$ slower than valid precue RT, with the older subjects showing a proportional increase over the younger subjects. Stelmach et al. observed no differential effects of motor plan restructuring across age with long PIs. Therefore, it appears that older subjects prepare movements in a manner similar to that of younger subjects, but more slowly (Salthouse, 1985). It is unclear, however, whether the degree or nature of preparation is the same for both age groups. If subjects are fully prepared, then when a parameter needs to be altered, it will cost time to restructure it; if subjects do not prepare, parameter alteration need not occur and similar RTs should be shown for all movement dimensions.

The long preparatory periods used in these earlier experiments create a problem in interpreting the results. It is possible that the negligible age effects observed in the restructuring tasks were due to a loss of preparation of the precued response due to a long preparatory period. 
Gottsdanker (1980a) suggested that older adults have difficulty maintaining response preparation. Thus, age differences with respect to motor plan restructuring may be present at shorter PI values, but are not present at long preparatory periods due to changes in the status of the motor plan. Amrhein, Stelmach, and Goggin (1989) found that older subjects are unable to maintain preparation of at least one parameter (direction) and, in fact, lost preparation over longer PI intervals.

The purpose of the present experiment was to investigate age differences in the preparation and restructuring of a motor plan with variable PIs of 500, 1,000, 1,500, and 2,000 msec between the precue offset and response stimulus onset. Furthermore, to determine the effects of parameter change restructuring, two parameters of movement, arm and direction, were varied. Parameter-specific effects are more likely to be found within a paradigm in which shorter and variable PIs are used to measure motor plan restructuring.

\section{METHOD}

\section{Subjects}

The subjects in this study were a younger age group (21-26 years) with a mean age of 22.7 years, and an older age group (63-76 years) with a mean age of 68.3 years. Each group contained 6 males and 6 females, who were closely matched in age, educational background, health status, and handedness (all subjects were right-handed). To determine if the subjects tested in this experiment were representative of their age-group populations, we examined scores from a subtest of the Wechsler Adult Intelligence Scale, the Digit Symbol Substitution Test (DSST). The DSST scores are generally interpreted as being indicative of overall psychomotor speed (Salthouse, 1985). The younger age group's mean score was 74.3 , and the older age group's mean was 47.7 (which correspond, respectively, to $82 \%$ and $53 \%$ of maximum). As found in previous studies (Salthouse, 1985; Stelmach et al., 1988), the DSST scores were negatively correlated with age $[r(11)=-.91, p<.001]$, indicating that the scores declined with increasing age.

\begin{abstract}
Apparatus
Each subject sat in a chair in front of a table that was $80 \mathrm{~cm}$ high in a soundproof testing chamber. The subjects were instructed to fixate on a visual light display that consisted of a square configuration of red LEDs with three yellow LEDs centrally located on a black board $70 \mathrm{~cm}$ from the subject. The position and colors of the LEDs on the board corresponded with the position of the keys on the response board.

The response keys were mounted on a 10.5- $\mathrm{cm}$-high box placed on the table and were configured in two columns of keys that were $21 \mathrm{~cm}$ apart and parallel to the sagittal plane. The Snap-Action momentary contact keys were raised $1 \mathrm{~cm}$ from the top surface of the box on metal shafts that fit into ball bearing sleeves so that contact with any portion of the target would close the switches. The yellow "home"' keys were $1.5 \mathrm{~cm}$ in diameter, and the red target response keys were $3 \mathrm{~cm}$ in diameter. The target response keys were arranged $7.1 \mathrm{~cm}$ above or below the home keys. The arrangement of the lights and target keys allowed for the manipulation of two movement parameters: arm (left/right) and direction (away/toward). The subjects were not permitted to look at their hands during a trial. The presentation of the stimuli and the recording of responses were controlled by an LSI-11/03 computer.
\end{abstract}

\section{Design and Procedures}

Each subject performed the restructuring task, with the testing session lasting approximately $2 \mathrm{~h}$. The subjects initiated a given trial by depressing the two yellow home keys. The yellow warning lights were then illuminated for $1.2 \mathrm{sec}$ to indicate that the subject should be ready for the upcoming precue and stimulus. One second after the onset of the warning light, the precue light was illuminated and remained on for $200 \mathrm{msec}$. There was a variable PI of $500,1,000,1,500$, or $2,000 \mathrm{msec}$ when no light was illuminated, which was immediately followed by a response stimulus light. The subject was instructed to release the home key that corresponded to the position of the response light (right or left) and to move to contact the response key that corresponded to the response stimulus light as quickly and accurately as possible. The interval from onset of the target stimulus to departure from the home key constituted the RT measure, whereas the interval from departure from the home key to contact with the target key was the movement time (MT) interval.

On $75 \%$ of the test trials in a given block, the target stimulus matched the precue stimulus (valid trials); on the remaining $25 \%$ of the trials, the target stimulus was different from the precue stimulus (invalid trials). In the invalid trials, subjects were required to restructure arm, direction, or a combination of the two parameters. The practice block and eight experimental blocks consisted of 48 test trials (36 valid and 12 invalid) and 6 catch trials. For each of the blocks, the valid and invalid trials were randomly sampled over the four PI values (with the only restriction being a $75 \% / 25 \%$ distribution per block).

\section{RESULTS}

All analyses are based on correct RT data collapsed over movement parameter levels for arm (left or right) and direction (toward or away). It should be noted that an analysis of the MT data yielded a large $(138 \mathrm{msec})$ age effect in which older subjects were slower $(321 \mathrm{msec})$ than younger subjects $(183 \mathrm{msec})$ in executing responses $[F(1,22)=1.40, p<.05]$. Analysis of total time data $(\mathrm{RT}+\mathrm{MT})$ indicated that the RT effects reported are independent of MT data.

\section{Valid and Invalid Precue Trials}

An overall analysis was carried out on the RT data, with age group, precue validity, and PI as factors. These data are shown in Figure 1, according to age group. There was a large effect for age group $[F(1,22)=32.6, p<.001]$, with older subjects responding $122 \mathrm{msec}$ slower than younger subjects. Valid precue RT was $70 \mathrm{msec}$ faster than invalid precue $\mathrm{RT}[F(1,22)=96.2, p<.001]$. Finally, there were changes due to $\operatorname{PI}[F(3,66)=15.4, p<$ $.001]$, in which RT decreased from $454 \mathrm{msec}$ at the 500 msec PI to $415 \mathrm{msec}$ at a PI of $1,000 \mathrm{msec}$ and remained generally constant at longer PIs (414 msec and $428 \mathrm{msec}$ at PIs of 1,500 and 2,000 msec, respectively). All remaining effects and interactions were nonsignificant (all ps $>.05)$.

\section{Invalid Precue Trials and Parameter Alteration}

Analyses were carried out on the RT data from the invalid precue trials to determine age differences due to specific movement parameters with respect to levels of PI. These data are the upper three curves for each of the two age groups in Figure 1. Overall, older subjects were slower $(529 \mathrm{msec})$ than younger subjects $(397 \mathrm{msec})$ $[F(1,22)=29.2, p<.001]$. There were also significant differences among the PI levels $[F(3,66)=11.0, p<$ $.001]$. Collapsing the curves across age group and valid and invalid trials indicated that RT decreased from $489 \mathrm{msec}$ at the $500-\mathrm{msec}$ PI to $454 \mathrm{msec}$ at the 1,000 - 


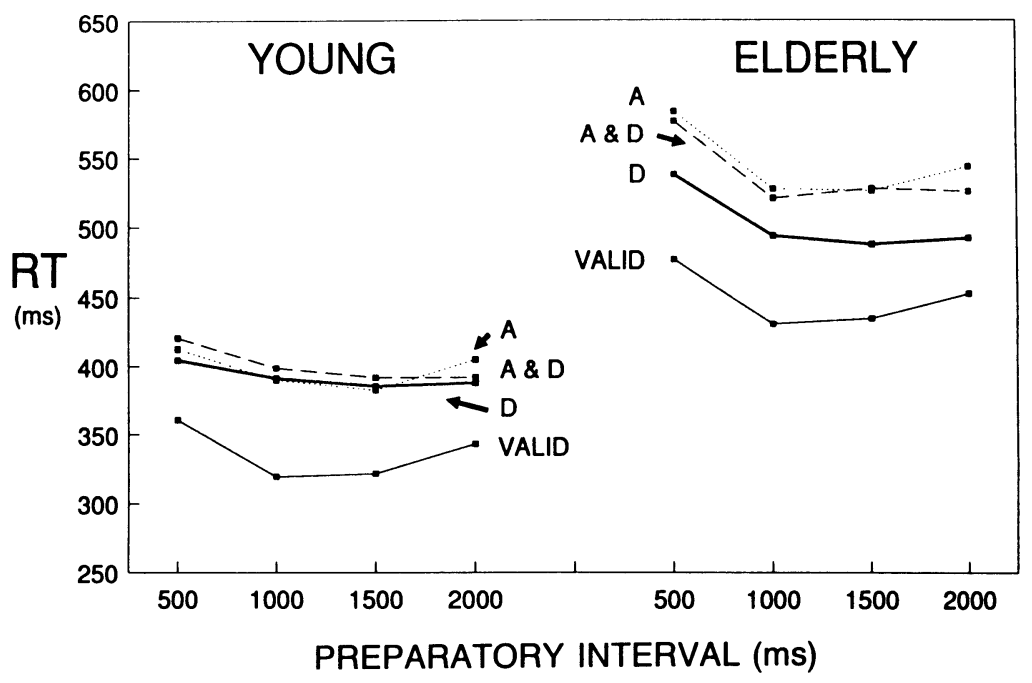

Figure 1. Age-related differences in valid and invalid trials across preparatory interval levels. $\mathbf{A}=$ arm. $\mathbf{D}=$ direction.

msec PI and remained generally constant at longer PIs (450 and $458 \mathrm{msec}$ at PIs of 1,500 and $2,000 \mathrm{msec}$, respectively). Movement parameter change interacted with age group $[F(2,44)=4.34, p<.02]$; direction restructuring, compared with the other two parameter change conditions combined, was easier for older subjects $(39 \mathrm{msec})[F(1,11)=17.1, p<.002]$ than for younger subjects $(6 \mathrm{msec})(F<1)$. As can be seen in Figure 1, this advantage for older subjects is consistent across PI levels. All other effects and interactions were nonsignificant (all $p s>.05$ ).

\section{DISCUSSION}

The older subjects in this experiment exhibited the general slowing phenomenon discussed by Salthouse (1985). In addition, it was found that older adults are able to use probability information to plan their motor responses. This can be observed in Figure 1, which indicates that valid precue trials produced faster RTs than those trials in which some movement restructuring occurred. This finding conflicts with the results reported by Rabbitt (1984) and Rabbitt and Vyas (1980) that elderly individuals are unable to utilize probability information.

Although earlier studies of motor plan restructuring and aging (Larish \& Stelmach, 1982; Stelmach et al., 1988) failed to find age-related restructuring effects, substantial age differences were observed in the present experiment. The use of a shorter precue stimulus interval and variable PI levels apparently increased the sensitivity of the movement restructuring paradigm to detect age differences in the preparation and restructuring of a movement. It appears that the length of the precue stimulus display interval is a critical factor in age-related restructuring studies. Gottsdanker (1982) reported similar effects. Younger subjects displayed no differences among the parameter change conditions in the invalid precue trials, whereas older subjects showed a $39 \mathrm{msec}$ advantage for altering direction relative to the other parameter change conditions. This effect was found over all PI levels and persisted at the 2,000msec PI level: Once a decrease in RT occurs for changing direction, this decrease remains over longer PIs. This lends support to the claim that little or no preparation of the direction parameter occurred with older adults. Stelmach et al. (1988) also showed that the RT for altering direction was less than that for altering arm. Therefore, since older adults do not prepare direction in advance (i.e., during the precue in- terval), there is less cost to restructure the precued movement. There is no need for them to restructure the parameter since it was not prepared. However, on the basis of results found by Amrhein et al. (1989), it is unclear whether older adults simply fail to prepare direction or lose preparation for direction over longer PIs.

The fact that arm and direction parameters show different profiles of preparation with age not only argues for their structural independence in motor plans, but also suggests that their basic organization is quite different. The benefit in RT for direction suggests that preparation for direction is absent in older adults, whereas arm seems to be prepared, and thus takes longer to restructure. These findings agree with those of Gottsdanker $(1980 \mathrm{~b}, 1984)$, who suggested that older adults have difficulty fully preparing for an upcoming stimulus. The parameter change conditions in this experiment provide the strongest argument for movement preparation differences in older adults; that is, preparation deficits appear to be localized in the motor plan when a given direction must be prepared. It is possible that older adults find muscle-specific preparation more difficult than do younger adults.

\section{REFERENCES}

Amrhein, P. C., Stelmach, G. E., \& Goggin, N. L. (1989). Age differences in the maintenance and restructuring of motor preparation. Manuscript submitted for publication.

Botwinick, J., Brinley, J. F., \& RobBin, J. S. (1959). Maintaining set in relation to motivation and age. Journal of Applied Psychology, 72, 585-588.

GOTTSDANKER, R. (1980a). Aging and the maintaining of preparation. Experimental Aging Research, 6, 13-27.

GotTSDANKER, R. (1980b). Aging and the use of advance probability information. Journal of Motor Behavior, 12, 133-143.

GotTSDANKER, R. (1982). Age and simple reaction time. Journal of Gerontology, 37, 342-348.

GotTsDanker, R. (1984). Effort of preparation and age. Perceptual \& Motor Skills, 59, 527-538.

Larish, D. D. , \& Stelmach, G. E. (1982). Preprogramming, programming, and reprogramming of aimed hand movements as a function of age. Journal of Motor Behavior, 14, 322-340.

Plamondon, R., Stelmach, G. E., \& Teasdale, N. (1989). Motor program coding representation: The use of advance information in the production of line responses. Manuscript in preparation.

RABBITT, P. M. A. (1984). How old people prepare themselves for events which they expect. In H. Bouma \& D. Bouwhuis (Eds.) Attention and performance $X$ (pp. 515-527). Hillsdale, NJ: Erlbaum. 
Rabbitt, P. M. A., \& Vyas, S. M. (1980). Actively controlling anticipation of irregular events. Quarterly Journal of Experimental Psychology, 32, 435-446.

Rosenbaum, D. A., \& Kornblum, S. (1982). A priming method for investigating the selection of motor responses. Acta Psychologica, 51, 223-243.

Salthouse, T. A. (1985). Speed of behavior and its implications for cognition. In J. E. Birren \& K. W. Schaie (Eds.), Handbook of the psychology of aging (pp. 400-426). New York: Van Nostrand Reinhold Publishers.

Stelmach, G. E., Goggin N. L., \& Amrhein, P. C. (1988). Aging and restructuring of precued movements. Psychology \& Aging, 3, 151-157.

(Manuscript received September 15, 1988.) 